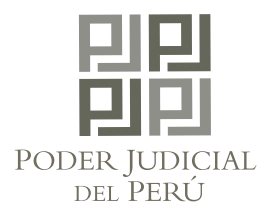

\title{
VI CONGRESO NACIONAL DE JUECES 2012
}

\section{DECLARACIÓN DE ICA}

Primero.- Invocamos se evalúe la mejora de estándares de carga procesal según la especialidad y la complejidad del expediente, así como la determinación de niveles de descarga en los cuales el número de expedientes conciliados y resueltos supere el número de ingresos, igualmente recomendamos la evaluación de medidas para la conversión de juzgados transitorios en permanentes.

Segundo.- Instamos a mejorar la planificación de Descarga procesal, mediante la determinación de objetivos y acciones a partir de la nueva Gerencia Operacional de Descarga, coordinando su monitoreo y evaluación con todos los órganos vinculados a dicho Plan.

Tercero- Requerimos perfeccionar los criterios de elaboración de estadísticas sobre producción jurisdiccional, y continuar con la unificación del sistema informático que permita una mejor medición del nivel de descarga.

Cuarto.- Saludamos el impulso, con la participación activa de los jueces, del desarrollo informático del Poder Judicial en los últimos años para establecer en el corto plazo un sistema de interconexión pleno dentro del Poder Judicial y en el mediano plazo un sistema de expediente digital, de acuerdo con los planes estratégicos trazados.

Quinto.- Nos comprometemos a colaborar con el cambio cultural en el Poder Judicial en cuanto a su desarrollo electrónico, para lo cual, sin embargo, necesitamos renovación de equipos informáticos, software, acceso pleno a internet y optimización de video conferencias.

Sexto.- Planteamos la realización de un trabajo conjunto para optimizar el uso del nuevo Data Center del Poder Judicial, tendiendo a maximizar creativamente su utilización en paralelo con una permanente capacitación. 
Sétimo.- Apoyamos la implementación de un sistema oral en los procesos judiciales de Familia, en todas sus subespecialidades, para lo cual es necesario continuar el debate del proyecto de ley de la Niñez y Adolescencia y consensuar un modelo de despacho judicial adecuado a la realidad logística de nuestro sistema de justicia.

Octavo.- Declaramos que en el tema de adolescentes en conflicto con la ley penal resulta fundamental ampliar la capacidad del sistema abierto a nivel nacional y descentralizar la ubicación de centros juveniles en los que se les capacite para el trabajo a los adolescentes como forma de reinserción social.

Noveno.- Consideramos de suma importancia el desarrollo de equipos multidisciplinarios de muy alto nivel en los procesos de familia, basados en exigentes niveles de selección, coordinación permanente con los jueces, capacitación y coordinación interinstitucional.

Décimo.- Reiteramos que el cumplimiento inmediato de la Ley Orgánica del Poder Judicial, en cuanto se refiere al sistema de remuneraciones de los jueces, es de vital importancia para trabajar por el desarrollo de todos los puntos anteriores percibiendo una remuneración digna, para lo cual se requiere la inmediata asignación de recursos del Poder Ejecutivo o la presentación del proyecto de ley consensuado con el Poder Judicial sobre la escala de remuneraciones de los jueces. 


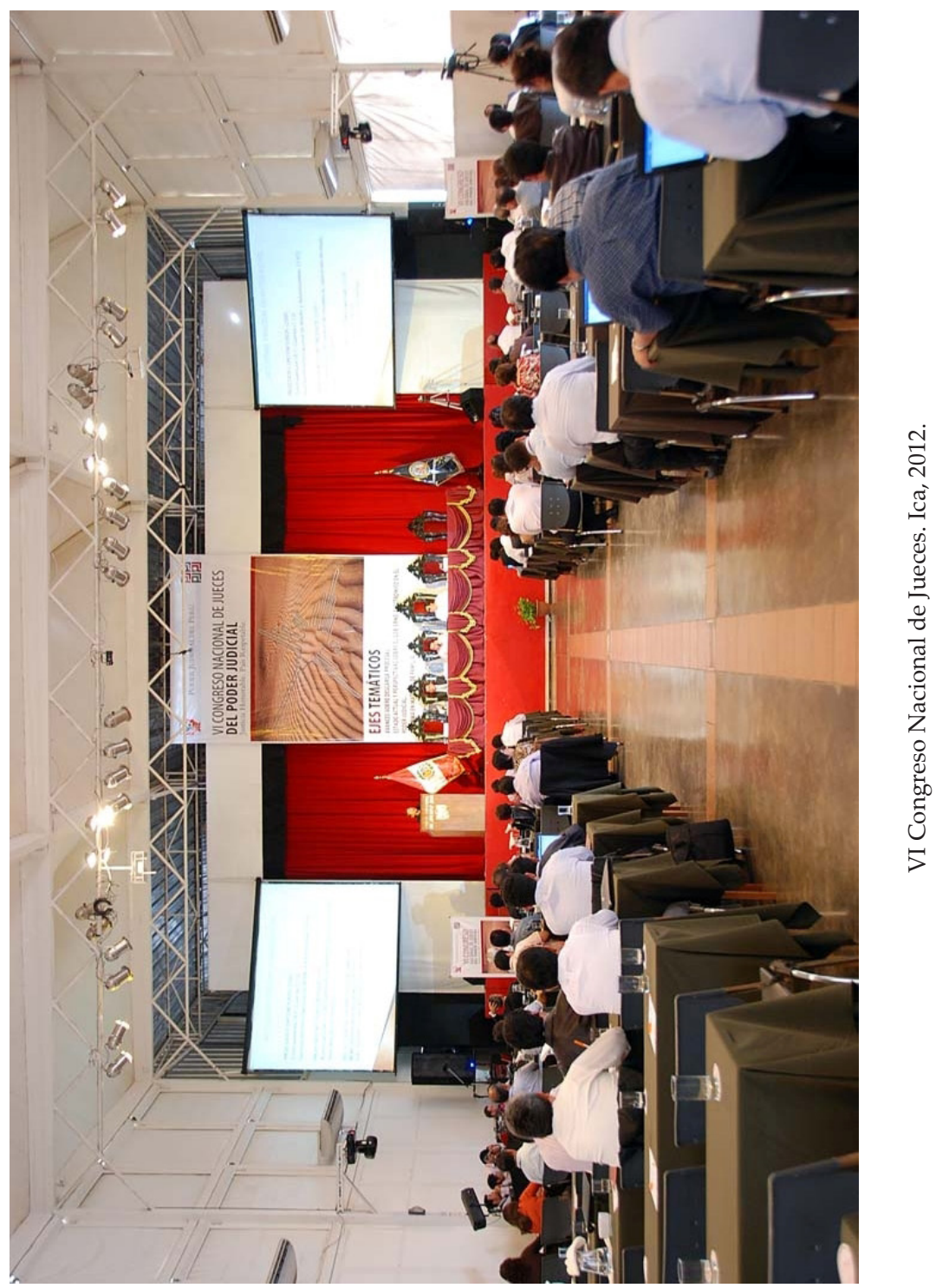

